\title{
Sobre a cultura do tempo e o livro didático de História
}

Yara Cristina ALVIM ${ }^{1}$

Sonia Regina MIRANDA ${ }^{2}$

RESUM0

0 presente artigo tem como objetivo analisar o processo de constituição da temporalidade nos livros didáticos de História contemporâneos. Parte do pressuposto de que este material é um produto complexo, cujo processo de produção está sujeito à intervenção de diversos agentes, integrando uma teia de saberes, valores e perspectivas teóricas. Assim, compreendemos que a constituição dos conteúdos veiculados no material didático está diretamente ligada a esta teia de saberes múltiplos, próprios do conhecimento histórico científico.

A partir dessa perspectiva, procuramos analisar o livro didático na sua relação com a historiografia moderna e a historiografia renovada, buscando perceber as formas pelas quais a temporalidade histórica é apresentada aos alunos e os valores e sentidos que emergem a partir de dessa apresentação.

0 artigo apresenta os resultados da investigação das coleções didáticas mais adotadas na cidade de Juiz de Fora, a partir do processo de escolha de livros didáticos do PNLD de 2005. 0 foco analítico concentra-se na análise da relação entre o conteúdo do livro didático e a produção histórica, bem como as relações entre a renovação historiográfica e o perfil das obras didáticas disponíveis para 0 mercado.

Palavras-chave: livro didático, temporalidade, ensino de história.

\section{0 livro didático em foco num percurso de pesquisa}

0 livro didático de História, em virtude da complexidade que lhe é inerente e que deriva de sua posição como importante artefato da indústria cultural,

1 Graduada em História pela Universidade Federal de Juiz de Fora. Mestranda em Educação do Programa de Pós-Graduação em Educação da UFJF. yaralvim@yahoo.com.br

${ }^{2}$ Doutora em Educação pela UNICAMP. Professora da área de Teoria e Metodologia do Ensino de História do Programa de Pós-Graduação em Educação da Universidade Federal de Juiz de Fora. sonia.miranda@ufjf.edu.br 
pode nos conduzir a campos reflexivos plurais e a fronteiras permanentemente abertas em termos de investigação quanto ao ensinar-aprender História. Talvez por esta razão o campo investigativo que traz o livro didático de História como objeto de pesquisa seja tão vasto e tão promissor, ainda que situado em torno de grandes questões longe de serem esgotadas e que podem nos conduzir tanto à análise dos usos e práticas sociais em torno do livro, como também de sua produção ou de seus valores e conteúdos (MUNAKATA, 2001; BITTENCOURT, 2004; CHOPIN, 2004).

Trata-se, fundamentalmente, de um material sujeito à intervenção de inúmeros agentes, que se interligam e que tanto constituem como são constitutivos de uma imbricada teia de saberes, valores, campos de conceituação, perspectivas teóricas, enfim, de uma cultura histórica ampla e plural. No livro didático, e em função dele, interagem autores, editores, avaliadores, professores, alunos. Talvez este caráter dinâmico e complexo do livro didático seja um dos elementos que façam dele um objeto que se situe na fronteira da historiografia moderna e da historiografia renovada, e também na fronteira entre a História e a Educação. Estes diversos agentes, por um lado, também se situam nesta multiplicidade de perspectivas historiográficas, que não são lineares e, por outro lado, interagem em espaços educativos plurais, portadores de perspectivas pedagógicas hỉbridas tributárias de tradições múltiplas e sincréticas.

Por esta razão, temos voltado nossa atenção, dentre outras temáticas inerentes ao ensino de História, também aos aspectos que se encontram por detrás dos usos do livro didático, bem como de sua produção. Mais recentemente, e no interior de uma trajetória de pesquisa em curso no Programa de PósGraduação em Educação, temos procurado lançar olhares mais aprofundados sobre as múltiplas vozes subjacentes aos pareceres avaliativos de livros didáticos de História, do Programa Nacional de Livros Didáticos do MEC. Tal conduta tem se dado a partir da adoção de uma perspectiva sócio-cultural, considerandose aqui as imbricadas dimensões analíticas que o pensador Mikhail Bakhtin atribui ao texto escrito e à polifonia que lhe é inerente (BAKHTIN, 1995). Nesta perspectiva, os pareceres serão analisados não como um texto monofônico, mas como arena em que inúmeras vozes sociais os constituem: o estado, os avaliadores, os editores, os autores e os professores.

Mas esse foco investigativo, que se encontra em curso e que trará como 
resultado uma dissertação de Mestrado a ser defendida no início de 2010, não se originou abruptamente, nem tampouco nasceu como um objeto descolado de uma reflexão que lhe seja anterior. Antes disso, ele é resultante de uma preocupação mais profunda, alicerçada sobre a necessidade de se compreender melhor os aspectos relativos às intersecções entre o livro didático e a produção histórica, bem como as relações entre a renovação historiográfica e o perfil das obras didáticas disponíveis para o mercado. Desse campo de interesses nasceu, entre os anos de 2005 e 2006, um projeto de pesquisa que culminaria na análise das obras didáticas mais adotadas no Estado de Minas Gerais e, particularmente, na cidade de Juiz de Fora a partir de um foco analítico particular: a forma como a temporalidade histórica é apresentada aos alunos e os valores que emergem a partir de tal apresentação.

Este artigo, portanto, tem o objetivo de apresentar ao público leitor aspectos de síntese daquela pesquisa e, com esse pressuposto, discutiremos, a seguir, como a historiografia tem lidado com as questões da temporalidade, a fixação de uma base cultural pautada na quadripartição histórica e seus efeitos sobre as obras didáticas. Nesse sentido, trata-se de uma análise que apresenta uma trajetória de pesquisa a partir de seus fios de passado, presente e futuro na constituição da própria subjetividade e desenvolvimento profissional do pesquisador.

\section{A temporalidade histórica como uma questão teórica no campo da História.}

Dentre muitas abordagens possíveis que podem emergir do interior do livro didático de História - que tanto pode ser focalizado em seus usos como em seus conteúdos - destaca-se a forma pela qual se associam as questões da temporalidade, da linearidade e da dimensão de totalidade preconizadas para 0 entendimento da História. Tais dimensões imbricam-se, numa teia conceitual que pode nos conduzir à fixação de uma visão sobre o tempo e sobre a perspectiva de progresso constituída em torno da idéia de passagem do tempo, conforme nos demonstram autores como Ciro Cardoso (1997) e Paolo Rossi (2005). Assim, acreditamos ser pertinente enveredar um pouco mais pela questão sobre a forma em torno da qual a temporalidade histórica tem sido evocada no interior das coleções didáticas.

As formas pelas quais as sociedades têm se relacionado com o passado 
variam de acordo com a organização social e com o desenvolvimento dos processos históricos das sociedades. A este respeito, Thompson (1998) elenca os diferentes tipos de percepção do passado pelas diferentes organizações sociais presentes na história. Segundo o autor, as sociedades tradicionais (ou sociedades camponesas) percebem o passado e, portanto, o tempo, de maneira cíclica. Já as sociedades modernas (ou sociedades urbano-industriais) adquiriram uma compreensão linear do tempo. Neste sentido, nestas sociedades, o passado é percebido como algo imutável, perdido no tempo e, por isso, irrepetível.

Para entender a constituição da temporalidade histórica, é essencial que se compreenda a natureza do passado. A esse respeito, Keith Jenkins (2004) nos aponta que passado e História não são a mesma coisa, embora possam ser vistos como elementos profundamente imbricados (Jenkins, 2001:23). Hobsbawm (1998) e Josep Fontana (1998) apontam para os usos sociais possíveis do passado, destacando seu uso como genealogia e como cronologia. 0 que cada grupo ou sociedade denomina como passado não é a totalidade do fato passado em si, tampouco o fato tal como ele ocorreu, mas "uma seleção particular daquilo que é lembrado" (HOBSBAWM,1998:23), com profundos efeitos em termos da constituição de um projeto identitário e que atravessa, diretamente, projetos de construção de hegemonia por parte de grupos sociais. Cabe destacar que esta forma de se "usar" o passado é bastante específica das sociedades modernas ocidentais e tem predominado na nossa maneira de perceber o presente e de projetar o futuro. Tal perspectiva, antes de posicionar a História como elemento potencial de análise e mudança social, situa-se na base constitutiva de uma tradição de pensamento que difundiu a perspectiva da "História como mestra da vida", como oráculo essencial e referencial moral dos elementos do presente. Assim, as formas pelas quais o passado é encarado repercutem diretamente na temporalidade histórica e criam formas específicas de se justificar o presente.

Portanto, o passado pode ser compreendido como criação humana, relacionada a formas particulares de organizações sociais. A este respeito, Norbert Elias (1998) destaca o caráter adquirido/aprendido do tempo e, portanto do passado. No que se relaciona às sociedades modernas, o autor destaca o caráter coercitivo, impositivo e, portanto, socialmente criado da percepção de tempo linear e de passado como instância fixa e anterior ao presente. A este respeito, 
0 autor utiliza o termo "processo civilizador", que se refere ao processo de internalização deste tipo de relação/percepção do tempo (ELIAS, 1998: 14).

A História, como saber científico institucionalizado, assume um papel significativo na fixação deste tipo de percepção de tempo e de passado no interior das sociedades modernas. A idéia de passado como categoria imutável no tempo tem sido uma das principais ferramentas do fazer histórico e uma das principais âncoras dessa perspectiva tem se dado a partir da fixação de uma narrativa histórica pautada na idéia de um tempo progressivo, homogêneo e unificador, como se fosse válido e referente para todos os povos e culturas (CHESNEAUX, 1986: 95; e ROSSI, 2000; ABUD, 1999).

Neste sentido, Dosse (2001) destaca o caráter legitimador da História em seu contexto de institucionalização, bem como a importância assumida pelo discurso histórico no sentido de constituir valores dominantes com relação às visões que se tornam hegemônicas quanto à História.

A História adquire os contornos de saber científico em finais do século XIX, momento de formação dos Estados-nação modernos. Neste contexto, a História assumia papel singular e primordial, na medida em que justificava a existência dos estados-nações a partir do resgate do passado. A este saber, caberia o papel de criar o sentimento de nacionalidade e, assim, criar o sentimento de coletividade entre os grupos sociais. Para tanto, os intelectuais (historiadores) buscavam no passado, neste passado imutável, elementos que reafirmassem 0 presente que agora se queria configurar. Dessa forma, a configuração do Estadonação era construída como um processo natural que se gestava no passado (DOSSE, 2001:13-18). Portanto, os fatos elencados deste passado justificavam o presente. Era como se as sociedades humanas tivessem evoluído em uma linha temporal, do passado para o presente.

A concepção histórica, pautada na relação linear entre passado, presente e futuro, tem marcado a historiografia moderna. Ainda que possamos perceber diferentes mudanças nas formas de estabelecimento de relações com o passado, a historiografia moderna tem se pautado pela percepção linear e evolutiva do desenvolvimento histórico. Esta forma de perceber o passado e de explicar 0 presente insere-se na matriz do pensamento filosófico dos séculos XVIII e XIX. 0 elemento que norteia esta lógica explicativa é a concepção progressista e evolutiva da história. Ciro Cardoso denominaria esta concepção explicativa de 
paradigma iluminista(CARDOS0,1997:03). A noção de história da humanidade como progresso rumo à civilização é, portanto, uma noção européia, particularmente francesa, que se alarga pelo mundo ocidental (CUCHE, 2002:22). A esta concepção linear do tempo associam-se operações históricas específicas de olhar para o passado e de compreender sua natureza.

A historiografia que se desenvolve em finais do século XIX herda os pressupostos da corrente positivista para a investigação histórica. A concepção progressista do espírito humano é transportada para o campo da história. A corrente positivista advoga que a humanidade teria seguido uma escala de desenvolvimento intelectual, seguindo do estado teológico ao estado científico ou positivo. Neste estado, o homem buscaria, através do uso da razão, as leis efetivas do universo. Ao historiador, ciente das leis da evolução social, caberia aplicá-las à investigação concreta, através da utilização de métodos científicos. Dentro desta perspectiva, a investigação do passado seria realizada pelo uso de métodos investigativos adequados que garantissem a apropriação da verdade do passado. 0 acesso ao passado era possível através da análise de documentos escritos. A aplicação de métodos investigativos rigorosos aos documentos garantiria a cientificidade da pesquisa e, portanto, o acesso à verdade dos fatos.

Como destaca François Dosse, o status de cientificidade do conhecimento histórico aí produzido, encobria seu caráter político-ideológico (DOSSE, 2001:13). Em primeiro lugar, o acesso ao passado era realizado sem a problematização das fontes. A verdade histórica era produzida através da investigação de documentos escritos e oficiais, que contavam a história dos grupos dominantes. Além disso, tais fontes não eram questionadas, mas encaradas como espelhos fiéis da verdade dos fatos. Em segundo lugar, 0 passado (encontrado nos documentos) buscava legitimar os interesses dos grupos dominantes, na medida em que a história resgatada era aquela que justificava o projeto político do Estado.

0 papel do historiador na legitimação do Estado nacional conduziu a um processo de "resgate" da história da nação. As ações e os grandes personagens do passado serviriam como base de justificação do presente e como modelos de inspiração para a coletividade. É neste mesmo contexto que a história, como saber escolarizado se institucionaliza. A instituição escolar e seus mecanismos de difusão do saber assumiam o papel de difusores do 
sentimento de nacionalidade e de coletividade. Os manuais didáticos de História constituem um importante veículo para difusão de valores ligados à nacionalidade. Estes materiais assumem um papel pedagógico singular, na difusão da história da nação, de seus heróis e de seus grandes feitos. A História da nação e da humanidade eram narradas a partir de uma estruturação temporal linear, em que os eventos se sucediam do passado até ao presente monárquico. A narrativa didática estruturava-se a partir da quadripartição histórica, que seguia a lógica histórica européia, mais especificamente francesa. Esta forma de escrever a História foi projetada pelos demais estados-nação modernos, estendendo-se ao Brasil. Tais marcas ainda permanecem fortes no ensino e nas obras didáticas brasileiras e será ancorada, fundamentalmente, sobre três importantes alicerces, que se destacam pelo peso que assumiram no tocante à constituição de um tipo de perspectiva quanto ao que deve ser ensinado às gerações mais jovens em termos de história: a idéia de que a operação histórica ocorre a partir de um referente de verdade inquestionável e absoluta, porque se ancora sobre documentos verídicos ou sobre narrativas sustentadas por testemunhas oculares; a perspectiva de análise pautada numa explicação em que a totalidade projeta-se como mito e meta; e a construção de uma explicação cuja narrativa ancora-se numa linearidade histórica e, nesse sentido, reforça a perspectiva de totalidade. Por esta razão é comum, ainda nos dias de hoje, nos depararmos com programas de História cuja construção reitera ou evoca tais princípios.

Dentro deste conjunto de pressupostos, destacamos algumas vertentes teóricas que, de diferentes modos, têm deixado marcas na forma de se estruturar narrativas históricas com uma perspectiva analítica total e progressiva, tais como o positivismo, o historicismo e o materialismo histórico.

0 Positivismo, ao rejeitar uma perspectiva problematizadora da relação investigativa em nome de uma perspectiva epistemológica de ênfase da neutralidade científica, acabou por reforçar uma compreensão fixa do passado. Nesta perspectiva, ao historiador, cabe o domínio dos procedimentos adequados para investigação dos documentos e, assim, fazer com que o passado seja ressuscitado. Há aqui uma concepção da objetividade histórica: um passado fixo e um historiador neutro, que saiba lidar de forma correta com os documentos. Não há aqui a problematização da subjetividade do historiador 
nem tampouco da fonte pesquisada. Ao historiador cabe revelar a origem dos acontecimentos, que se encontra neste passado estável. o passado explica, assim, o presente, e converte-se, portanto, em uma base de consciência pautada na exemplaridade das lições que devem ou não ser "repetidas" voluntariamente.

Estes pressupostos implicam relações específicas com o tempo bistórico: se o passado está ali, imóvel, basta ressuscita-lo e assim, encontrar a explicação para 0 presente. "0 tempo histórico segue uma linha homogênea e vazia, onde os acontecimentos se encaixam" (GAGNEBIN, 1993, 54).

Em um caminho epistemológico sensivelmente distinto, o Historicismo e o marxismo problematizam, de modos distintos, a relação do historiador com 0 passado, enfatizando sua subjetividade neste processo. Neste sentido, trazem contribuições teórico-metodológicas significativas. Contudo, não rompem com a perspectiva de progresso que pauta a explicação histórica. Apesar das diferentes relações que estabeleciam com os objetos e os diferentes aportes teóricometodológicos que os embasam, tais vertentes têm em comum a continuidade com a tradição do pensamento iluminista, conforme nos demonstrara Ciro Cardoso (1997). Mantêm-se, desta forma, aquilo que Chesneaux denomina de quadripartismo histórico: a história continua sendo encarada sob a ótica do processo histórico linear, norteada pela lógica da história européia. A história estrutura-se a partir dos quatro grandes momentos históricos: História Antiga, História Medieval, História Moderna e História Contemporânea. 0 marxismo ou, mais precisamente, uma leitura marxista pautada pela simplificação e por uma perspectiva sensivelmente revisionista em relação aos cânones elaborados pelo próprio Marx, mantêm este quadro sob novas roupagens: a idéia de uma evolução progressiva dos modos de produção. Ou seja, o tempo histórico, ainda que evocado sob o ponto de vista do entendimento de suas contradições continua se pautando por uma narrativa linear e constituída em função do epicentro europeu.

A partir da década de 1970 este conjunto de postulados passou a sofrer numerosas críticas e enfrentou um notável processo de reformulação. Ainda que este processo tenha se estendido para o conjunto das ciências sociais, destacaremos aqui as transformações que se operam no campo do conhecimento histórico. As críticas giravam em torno da inadequação da História e de seus métodos às demandas do mundo contemporâneo. Algumas perspectivas 
emergem nesse contexto, deslocando o campo reflexivo tradicionalmente constituído sobre a História e a temporalidade, conforme nos demonstram alguns autores contemporâneos (CARDOSO, 1997; DOSSE, 1992 e 2001; RAG0, 2003) a descrença nos princípios da razão e da modernidade, sobre os quais a História se erigiu, e junto com eles o questionamento à noção histórica de progresso - sob a acusação de que não teria conduzido a humanidade à liberdade e à felicidade. Com isso, emerge uma notável descrença quanto à existência de uma explicação universal da história. A universalidade passa a ser vista como algo que se limita ao ocidente, de onde emerge a constatação de que vivenciamos temporalidades diferenciadas e simultâneas. Junto com isso, projeta-se a crença de que não há uma só maneira de se escrever a história, e junto com essa tomada de consciência, o questionamento contra as metanarrativas, acusadas de não esclarecerem os processos políticos e sociais complexos da sociedade contemporânea. Assim, a problematização da ciência histórica em termos de seus métodos e pressupostos, de suas representações do tempo e do passado, faz com que um novo conceito de temporalidade surja. Conforme nos destacara Margareth Rago (2003) da idéia de passado como lição e resposta para o presente, passa-se à idéia da historicidade, ou seja, da historicidade dos fenômenos.

Neste contexto justifica-se o resgate exuberante de pensadores que, em uma época anterior, não haviam recebido o devido destaque no campo intelectual. Tal fato ocorrera, por exemplo, em relação ao pensamento de Walter Benjamin. Ainda que suas obras tenham sido escritas no início do século XX, Benjamin adquire notoriedade no Brasil na década de 1980, momento crucial de renovação do pensamento histórico. Benjamin destaca 0 passado como ato humano de evocação a partir do olhar do presente. Dessa forma, os homens buscam o passado a partir de seu olhar do presente. Longe, portanto, de uma concepção naturalizante e imutável do passado, este adquire formas particulares em contextos sociais específicos. Com isso, emerge no pensamento benjaminiano uma significativa crítica à concepção mutável do passado e à naturalização do processo histórico. Ao mesmo tempo, destaca-se com bastante ênfase a crítica à objetividade do historiador e à idéia de uma história universal, baseada na noção de progresso. Ao criticar a concepção do tempo como cronologia linear, e junto com ela não só a idéia de causalidade 
histórica, bem como o nexo causal entre os diferentes momentos da história, Benjamin contrapõe a esta concepção de tempo ao "tempo do agora". A relação do historiador com o passado é colocada sob a perspectiva do presente, ou seja, o sujeito olha para o passado de acordo com o momento em que vive e com suas intenções. Deste modo, aquele autor propõe o estilhaçamento da cronologia da história, que só teria servido para contar a história dos vencidos. 0 estilhaçamento da cronologia significa a realização de saltos e de recortes inovadores do passado, que possibilitem resgatar o passado dos vencidos.

Em certa medida, ainda que evocando bases filosóficas distintas e em temporalidades distintas, não deixa de haver similaridades entre o pensamento benjaminiano e 0 quadro de mudanças que passam a caracterizar o processo de renovação no campo do pensamento histórico que se faz sentir, com mais vigor, a partir dos anos 60 , por meio de pensadores que preconizam uma dimensão de desconstrução e ruptura de uma temporalidade cronológica, linear e evolutiva. Contudo, as marcas das tradições anteriores sobre a constituição de uma cultura histórica e de uma perspectiva temporal canônica continuariam se fazendo sentir, com algumas marcas indeléveis, sobre as obras didáticas disponíveis para o mercado e, sobretudo, para a organização de princípios referentes para a educação dos jovens.

\section{A temporalidade e o livro didático de História: uma análise empírica}

0 processo de investigação da temática relativa à constituição da temporalidade histórica nos livros didáticos produzidos na contemporaneidade revelou um cenário dominante, que se reafirmou na análise empírica de três obras didáticas selecionadas para o projeto de pesquisa então em desenvolvimento. Como já haviam destacado Miranda e Luca (2004) - em artigo que focalizava as principais tendências dos livros didáticos de História aprovados pelo PNLD de 2005 - a estruturação temporal quadripartite emergia como tendência dominante no conjunto destas coleções. Do total das obras, 76\% estruturavam-se a partir da perspectiva histórica denominada História Integrada, 7\% em História Nacional e apenas 17\% em História Temática ${ }^{3}$

3. As denominações História Integrada, História Nacional e História Temática foram retiradas do Guia de 2005. Referem-se a uma categorização das coleções didática de acordo com a organização temporal e espacial que 
(MIRANDA \& LUCA, 2004:139). Dessa forma, no mínimo 83\% das coleções presentes nos Guias adotavam a quadripartição histórica como eixo estruturador de seus conteúdos.

A análise pragmática das coleções também apontou para um cenário semelhante. Diante de um vasto número de obras didáticas aprovadas pelo PNLD de 2005, selecionamos três coleções. Para tanto, foi realizado um rastreamento das coleções didáticas adotadas pelas escolas públicas da cidade de Juiz de Fora a partir das informações disponíveis no site do FNDE quanto às escolhas em primeira e segunda opção, e as obras entregues às escolas. De um universo de 93 escolas, selecionamos as três coleções que obtiveram o maior número de pedidos, a saber: Nova História Crítica, História em Documento, Imagem e Texto e História e Vida Integrada.

0 gráfico abaixo ilustra a frequiência de pedido, por escolas, das três obras que obtiveram maiores números de escolhas pelos professores.

\section{Quadro 1}

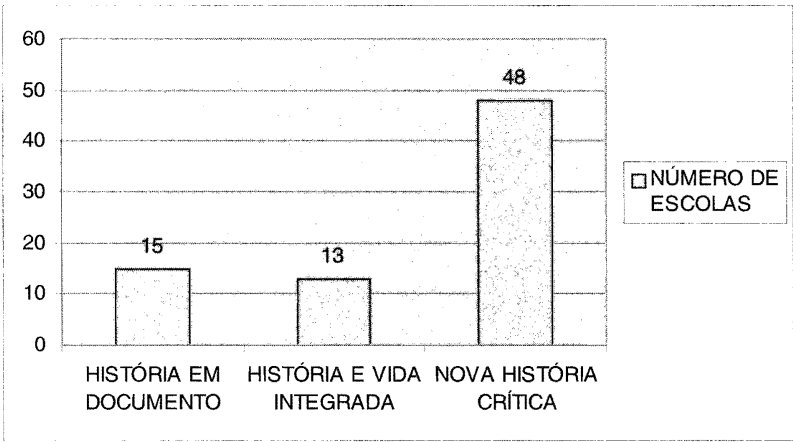

0 mapeamento do processo de escolha das coleções didáticas na cidade de Juiz de Fora revelou um outro cenário interessante, relacionado com as preocupações orientaram nossa pesquisa. Percebemos a predominância da

atribuem aos acontecimentos históricos. 0 termo História Integrada abrange coleções que abordam simultaneamente a História Geral com as Histórias do Brasil e da América, estabelecendo relações entre elas. A perspectiva centrada na denominação História Nacional centra-se na abordagem de temáticas relativas à história do Brasil nos dois primeiros volumes da coleção ( $5^{\mathrm{a}} \mathrm{e} 6^{\mathrm{a}}$ séries) e na História Geral nos dois últimos volumes $\left(7^{\mathrm{a}}\right.$ e $8^{a}$ séries). Já o termo História Temática refere-se às coleções que privilegiam o trabalho com conceitos e que propõem o abandono da perspectiva cronológica na estruturação de suas coleções. 
perspectiva histórica norteada pela História Integrada entre a totalidade de obras didáticas adotadas pelo município. Esta perspectiva era, naquele momento, a que também orientava as três coleções didáticas selecionadas para a investigação empírica. 0 quadro abaixo revela este cenário. Podemos perceber que, do conjunto das escolas (93), 86 adotaram coleções que se orientavam pela perspectiva integrada.

\section{Quadro 2}

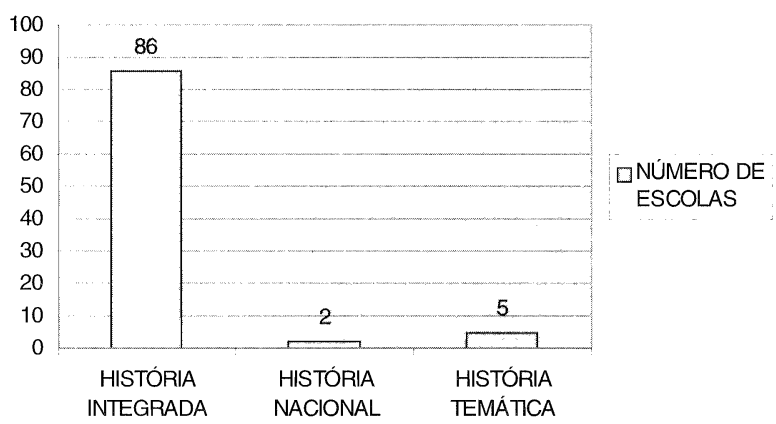

A adoção maciça desta perspectiva temporal nos conduziu a um olhar mais apurado para o sentido atribuído a esta estruturação. Como explicita 0 Guia de Livros Didáticos de História de 2005, a singularidade desta estruturação centra-se no tratamento simultâneo e linear dado aos conteúdos de História do Brasil, da América e Geral. Foi, a partir desse olhar, que buscamos, naquele momento, analisar as três coleções didáticas.

A análise das três coleções foi realizada a partir de dois movimentos. Em um primeiro momento, procuramos investigar as propostas teórico-metodológicas de cada coleção, explícitas no manual do professor. Em seguida, fizemos a análise de cada coleção no que se refere à forma pela qual os conteúdos são inseridos e encadeados. Esta investigação revelou um quadro interessante e, muitas vezes discrepante no que tange à proposta apresentada e a sua efetivação no conjunto das coleções. Tal quadro nos apresentou, particularmente, avanços e recuos em relação à abordagem teórica e metodológica da História e que se refletiram na estruturação da temporalidade histórica.

A análise do Manual do Professor das três coleções revelou um discurso 
pautado pela adoção de perspectivas que convergiam para a renovação teóricometodológica tanto no campo da historiografia quanto no campo do ensino de História. Nos manuais é evidente a preocupação com a formação da cidadania, através de um discurso da tolerância, do reconhecimento das diferenças e do desenvolvimento da criticidade dos alunos. Os manuais apontam também a preocupação no estabelecimento de relações entre passado e presente, assim como com o resgate e valorização dos diferentes sujeitos históricos. A preocupação com temáticas relativas à preservação do meio ambiente, do patrimônio histórico e cultural é recorrente nestes documentos.

Contudo, ao adentrarmos na análise do conjunto das obras, percebemos que, muitas vezes, as propostas não são integralmente efetivadas. Quando o são, pautam-se por bases conceituais e metodológicas tradicionais. No que se refere ao objeto de estudo da pesquisa em questão, pudemos perceber esta relação no que se refere à constituição da temporalidade histórica das três coleções didáticas.

A análise das coleções revelou-nos aspectos comuns no que se refere à temporalidade. Em primeiro lugar, destacamos a estrutura temporal baseada naquilo que Chesneaux denominou de quadripartismo histórico (CHESNEAUX, 1986: 92). Neste sentido, percebemos, no decorrer das três coleções, a divisão do processo histórico em quatro grandes blocos, a saber: História Antiga, História Medieval, História Moderna e História Contemporânea. Neste sentido, notamos a permanência da lógica cronológica européia, baseada numa perspectiva de causalidade histórica. Permanece, assim, a noção evolutiva do tempo e dos eventos históricos, onde as permanências são silenciadas. Herdada do século XIX, a estrutura temporal linear e progressiva, mantém-se hegemônica nas obras didáticas contemporâneas de História.

A despeito da permanência da estrutura cronológica ocidental, observase nestas coleções a tentativa de incorporação de diferentes realidades históricas ao grande eixo cronológico linear. Neste sentido, as coleções recorrem à incorporação dos conteúdos de História do Brasil e História da América à grande estrutura de História Geral. Essa organização - conhecida por História Integrada - abre espaço para outras realidades históricas e, dessa forma, para um diálogo com o fazer histórico oriundo da historiografia renovada. Entretanto, destacamos que a incorporação destas diferentes realidades se dá a partir do referencial temporal ocidental. A história dos povos não-ocidentais é encaixada dentro do grande esquema quadripartite. 
Podemos ilustrar esta relação em diferentes momentos das obras. Situação peculiar encontra-se na coleção Nova História Crítica, em que a História da América é tratada a partir da lógica histórica européia, embora se situe em diferentes momentos de cada volume das quatro séries escolares. A primeira inserção desta temática ocorre no volume da quinta série, dentro do capítulo 2 - "A Pré História" - em um tópico intitulado "A Pré-História da América". Logo em seguida, aparece o capítulo 3, intitulado "0 Começo da História", começo este identificado a partir da Mesopotâmia. Assim, permanece a tendência de relacionar o começo da História com as "grandes" civilizações da antiguidade oriental. Nos volumes de $6^{a}$ série a História da América é retomada. Nas três coleções, sua inserção ocorre a partir da lógica histórica européia, ressurgindo como desdobramento da expansão marítima européia. É o que verificamos, por exemplo, no volume Nova História Crítica, em que o próprio título do capítulo reafirma esta tendência. Sob o título "América antes dos Europeus", o capítulo aborda a existência de diferentes povos no continente, destacando a diversidade dos grupos indígenas. Aponta sua diversidade de experiências, reduzida, contudo, aos aspectos sócio-econômicos. 0 capítulo seguinte - "Conquista da América" - parece reafirmar a existência do capítulo anterior como pretexto para discutir a conquista européia no continente.

0 mesmo ocorre com a História da África. Apesar de algumas diferenças no enfoque, as três coleções promovem uma abertura tímida e parcial aos temas relacionados à África, inserindo-os a partir dos volumes de $6^{a}$. série, no contexto da exploração colonial portuguesa.

Podemos verificar com clareza esta relação na coleção História em Documento. Nesta coleção, a África insere-se na Unidade 4 - "A colonização do Brasil" - após dois capítulos dedicados ao processo de colonização e à utilização da mão-de-obra escrava. Ao final do capítulo 15 - "De que forma 0 Brasil enriquecia sua metrópole?" - dedica-se à seção Refletindo sobre a História à África. Intitulada "AÁfrica antes dos portugueses" esta seção ressalta a presença de grandes civilizações no continente africano, que remontam a Antiguidade. Assim como nas duas coleções acima, o discurso volta-se para a valorização do papel dos africanos na História e de suas contribuições e influências no mundo colonial.

A despeito da ênfase dada ao mundo africano, sua inserção se dá a partir 
da lógica temporal européia. A existência remota desses povos no continente é ressaltada, porém sua abordagem não se efetiva no seu contexto próprio Antiguidade. Apenas é mencionado no volume da $6^{a}$. série, voltado para a Idade Moderna.

A retomada da África nas três coleções didáticas ocorre nos volumes de $7^{a}$.série, em capítulos referentes à expansão imperialista da Europa. É o que se verifica no capítulo 19- "0 neocolonialismo" do volume História e Vida Integrada e no capítulo 16- "Por que os países industriais dividiram o mundo entre si" do volume Historia em Documento, por exemplo, onde são abordados o processo de divisão do continente pelas potências imperialistas e seus reflexos sobre a população local.

Nos volumes de $8^{\mathrm{a}}$.série, dedicados ao mundo contemporâneo, a África ressurge, ainda que na perspectiva histórica européia. No volume História e Vida Integrada, há um capítulo - capítulo 10: "A independência das colônias da África e da Ásia e o fim do apartheid na África do Sul"- dedicado ao processo de descolonização da África, juntamente com a Ásia. Destaca-se ao final deste capítulo o regime de apartheid da África do Sul, algo que não aparece na coleção Nova História Crítica. Já no volume História em Documento, no interior da unidade 2 "0 mundo bipolarizado" - dedica-se um tópico aos impactos da Guerra Fria na África, assim como na Ásia, no Oriente Médio e na América Latina.

A análise das três coleções nos revelou a permanência de uma perspectiva linear e progressiva do tempo, assentada na lógica temporal européia. Contudo, a abertura a outros recortes, a partir da abordagem de diferentes povos constitui uma tendência destas coleções. A abordagem da singularidade de cada povo e a ênfase dada ao seu papel significativo na História são alguns aspectos abordados no decorrer dos conteúdos das coleções. Tal abertura insere-se na perspectiva apresentada nos Manuais do Professor, em que a valorização das diferentes experiências históricas, dos papéis que os diferentes sujeitos assumiram na história e da necessidade de reconhecer as diferentes culturas surgem como pressupostos para que o aluno seja capaz de reconhecer e respeitar as diferenças.

Embora as resenhas dos Guias referentes às três coleções apontem renovações significativas destas obras no campo da metodologia e da abordagem históricas (como a relação entre passado e presente - verificada na resenha da coleção História e Vida Integrada, p.65 - a não identificação da História a heróis e datas - visível na resenha relativa da coleção História em Documento, 
imagem e texto, p. 57 - a incorporação da renovação historiográfica através do tratamento de temáticas como a vida cotidiana - presente na resenha da coleção História e Vida Integrada, p.67 e o tratamento da diversidade de agentes que fazem parte da história - verificável na resenha da coleção Nova História Crítica, p.135), permanece, nestas obras, a quadripartição como elemento norteador dos conteúdos.

Dessa pesquisa, podemos perceber o peso do referencial temporal linear e quadripartite como eixo norteador da organização do processo histórico. Tal fato pode ser constato tanto nos Guias de 2005, quando a grande maioria das coleções didáticas segue esta estruturação, quảnto no processo de escolba dos professores, como constatado na pesquisa da cidade de Juiz de Fora. Embora tenha ocorrido um processo de renovação dos métodos e das abordagens históricas nos livros didáticos, alguns referenciais tradicionais - como a cronologia constituída em função de uma perspectiva de temporalidadecontinuam sensivelmente enraizados.

Após esta pesquisa passamos a perceber que ampliar o grau de reflexividade entre os campos de diálogo próprios da ciência histórica e o campo de produção dos livros didáticos de História, como já tem feito autores como Décio Gatti (2004), tende a nos abrir novos horizontes para compreender melhor a relação de diálogo e interações entre esses dois campos. Talvez essa interseção possa vir a abrir, para nós e para outros pesquisadores, uma compreensão mais bem fundamentada acerca de como a renovação historiográfica manifesta-se na indução do mercado editorial didático. Temos procurado faze-lo a partir de um olhar sobre os efeitos processados pelo programa de avaliação do livro didático de História e, no momento, encontramo-nos em meio a uma nova trilha investigativa. Esperamos que desta trilha novos elementos possam emergir no sentido de elucidar melhor esse campo de pesquisa marcado por enorme densidade e complexidade.

\section{Referências}

ABUD, Kátia Maria. Temporalidade e didática da história. In: Anais do III Encontro de Pesquisadores do Ensino de História. Campinas, SP, 1999.

BAKHTIN, Mikhail M. Marxismo e filosofia da linguagem. São Paulo: Hucitec, 1995. 
BITENCOURT, Circe Maria Fernandes. Apresentação. Educação e Pesquisa, 2004, vol.30, n.3.

CHESNEAUX, Jean. Devemos fazer tabula rasa do passado? São Paulo, Brasiliense, 1986

CHOPIN, Alain. História dos livros e das edições didáticas: sobre o estado da arte. Educação e Pesquisa, 2004, vol.30, n. 3, ISSN 1517-9702

CARDOSO, Ciro Flamarion. História e paradigmas rivais. In: \& VAINFAS, Ronaldo. Domínios da História. Rio de Janeiro, Campus, 1997.

CUCHE, Denys. A noção de cultura nas ciências sociais. $2^{\text {a }}$ edição, Bauru: EDUSC, 2002.

DOSSE, François. A História em Migalhas. Campinas, UNICAMP, 1992.

- A História à prova do tempo: da história em migalhas ao resgate do sentido. São Paulo, UNESP, 2001.

ELIAS, Norbert. Sobre o tempo. Rio de Janeiro, Jorge Zahar, 1998.

FONTANA, Josep. História: análise do passado e projeto social. São Paulo, EDUSC, 1998.

GAGNEBIN, J.M. História e narração em Walter Benjamin. São Paulo: Perspectiva, 1994.

GATTI, Décio. A escrita escolar da História. Bauru, Edusc, 2004,

Guia de Livros Didáticos 2005: v.5: História. Brasília: Ministério da Educação, Secretaria de Educação Infantil e Fundamental, 2004.

HOBSBAWM, Eric J. Sobre História. São Paulo: Companhia das Letras, 1998.

JENKINS, Keith. A História repensada. 2ªed. São Paulo: Contexto, 2004.

MUNAKATA, Kazumi. Histórias que os Livros Didáticos contam, depois que acabou a ditadura no Brasil. In: FREITAS, Marcos Cezar de (org). Historiografia brasileira em perspectiva. $4^{\mathrm{a}}$ ed, São Paulo: Contexto, 2001.

MIRANDA, Sonia Regina; LUCA, Tânia Regina de. O livro didático de História boje: um panorama a partir do PNLD. Revista Brasileira de História. São Paulo, v.24, p.123-144, 2004.

RAGO, Margareth. 0 historiador e o tempo. In: ROSSI, Vera Lucia Sabongi; ZAMBONI, Ernesta. (orgs.). Quanto tempo o tempo tem! Campinas, SP: Alínea, 2003

ROSSI, Paolo. Náufragios sem espectador. São Paulo, UNESP, 2000. 
THOMPSON, E. P. Tempo, disciplina de trabalho e capitalismo industrial. In:

. Costumes em comum. São Paulo, Companhia das Letras, 1998.

COLEÇÕES ANALISADAS:

PILETTI, Cláudio; PILETTI, Nelson. História e Vida Integrada. São Paulo: Ática, 2002. RODRIGUES, Joelza Ester. Historia em Documento: Imagem e Texto. São Paulo: FTD, 2001.

SCHIMDT, Mário Furley. Nova História Crítica. São Paulo: Nova Geração, 2002.

\section{About The Culture of The Time And The Textbook of History}

ABSTRACT

This article aims to analyze the process of formation of temporality in the history of contemporary textbooks. Based on the assumption that this material is a complex product whose production process is subject to the intervention of several agents, integrating a web of knowledge, values and theoretical perspectives. Thus, we understand that the creation of content run on educational materials is directly linked to this web of multiple skills, own history of scientific knowledge. From that perspective, trying to analyze the textbook in their relationship to modern history and historiography renewed, seeking understand the ways in which the historic temporality is presented to students and the values and meanings that emerge from this presentation.

The article presents the results of research collections of more didactic adopted in the city of Juiz de Fora, from the process for choosing textbooks PNLD of 2005. The analytical focus will focus on analyzing the relationship between the content of the textbook and historic production, as well as relations between the historiographical renewal and the profile of didactic works available to the market.

Keywords: textbook, temporality, teaching of history. 